\begin{tabular}{ccc}
\hline International Journal of Engineering \& Technology, $7(4.30)(2018) 342-346$ \\
SPC \\
Website w ww. sciencepubco.com/index.php/IJET \\
Research paper
\end{tabular}

\title{
Forecasting Electricity Consumption Using Fuzzy Time Series
}

\author{
K.G. Tay ${ }^{1 *}$, Y.Y. Choy ${ }^{2}$, C.C. $\mathrm{Chew}^{3}$ \\ ${ }^{1}$ Department of Power Engineering, Faculty of Electrical and Electronic Engineering, UTHM \\ ${ }^{2}$ Department of Mathematics, Faculty of Applied Science and Technology, UTHM \\ ${ }^{3}$ Department of Computer Engineering, Faculty of Electrical and Electronic Engineering, UTHM \\ *Corresponding authorE-mail: tay@uthm.edu.my
}

\begin{abstract}
Electricity consumption forecasting is important for effective operation, planning and facility expansion of power system. Accurate forecasts can save operating and maintenance costs, increased the reliability of power supply and delivery system, and correct decisions for future development. There is a great development of Universiti Tun Hussein Onn Malaysia (UTHM) infrastructure since its formation in 1993. The development will be accompanied with the increasing demand of electricity. Hence, there is a need to forecast the UTHM electricity consumption for future decisions on generating electric power, load switching, and infrastructure development. Therefore, in this study, the Fuzzy time series (FTS) with trapezoidal membership function was implemented on the UTHM monthly electricity consumption from January 2011 to December 2017 to forecast January to December 2018 monthly electricity consumption. The procedure of the FTS and trapezoidal membership function was described together with January data. FTS is able to forecast UTHM electricity consumption quite well.
\end{abstract}

Keywords: Fuzzy time series; FTS; MAE; MAPE; MSE; RMSE.

\section{Introduction}

Time series is a collection of equally spaced temporal data. A time series can consist some or all of the components such as trend (long term pattern), cyclical (repeated up and down movements), seasonal (regular fluctuations during the same month or quarter) and irregular (unexplained random component)[1].

Zadeh [1] was the first to propose the concept of fuzzy set theory. Song and Chissom [2] presented the definition, properties and procedure to develop a first-order time-invariant Fuzzy time series (FTS) model based on Zadeh's [3-6] works. Their definition of FTS is as follows:

Let $Y(t)(t=\ldots, 0,1,2, \ldots)$, be a time series , a subset of $R$ and be the universe of discourse on which fuzzy sets $f_{i}(t)(i=1,2, \ldots)$ are defined. Let $F(t)$ be a collection of $f_{i}(t)$. Then, $F(t)$ is called a fuzzy time series on $Y(t)(\mathrm{t}=\ldots, 0,1,2, \ldots)$.

Forecasting is predicting future values based on past and current time series data. Forecasting for future load demand is essential for future power system planning and control. Load forecasting can be divided into short-term load forecasting (STLF), mediumterm load forecasting (MTLF) and long-term load forecasting (LTLF). STLF up to one day or one week at most, MTF ranges from one day to several months while LTF forecasts more than a year ahead) [7]. STLF is used for scheduling the generation and transmission of electricity, MTLF is used to plan the fuel purchases, whereas LTLS is aimed to develop the power supply and delivery system (generation units, transmission system, and distribution system) [8].

Song and Chissom [9] applied first-order time-invariant FTS on the enrolment of Alabama University from the years 1971-1990. Their proposed procedure using FTS to forecast are as follow:
1. Define the universe of discourse

$$
\mathrm{U}=\left[D_{\min }-D_{1}, D_{\max }+D_{2}\right]
$$

2. Partition the universe of discourse into several even equal length intervals as $u_{1}, u_{2}, \ldots, u_{r n}$.

3. Define some fuzzy sets on the universe.

4. Fuzzify the historical data using the memberships of each year's enrollment in each fuzzy set $A_{i}$.

5. Derive fuzzy logical relationship (FLR). $R_{i}=A_{j}^{T} \times A_{k}$, for all $n$ relations $A_{j} \rightarrow A_{k}, \quad R=\bigcup_{i=1}^{n} R_{i}$ where $\times$ is the min operator, $T$ is the transpose operator, and $U$ is the union operator.

6. Forecasted output using $A_{i}=A_{i-1} \circ R$, where $A_{i-1}$ and $A_{i}$ are the fuzzified enrollments of year $i-1$ and $i$ represented by a fuzzy set. The symbol o denotes the Max-Min composition operator.

7. Defuzzify forecasted results.

In [9], Song and Chissom's forecasting method requires a huge computation to derive the fuzzy relation $R$ and the max-min composition operator when the fuzzy relation $R$ is very big.Song and Chissom [10] applied time-variant FTS models with a three-layer back-propagation neural network to convert the output and compared three different defuzzification methods on the enrolment of Alabama University from the years 1971-1992. They also investigated the difference of time-invariant [9] and time-variant [10]. Results showed that the neural network model yielded the smallest average forecasting error. Their procedure is similar with Song and Chissom [9] from steps 1-5 except the fuzzy relation $R$ was defined as 


$$
\begin{gathered}
R_{i}=f^{T}(t-i) \times f^{T}(t-i+1) \text { for all } n \text { relations } \\
A_{j} \rightarrow A_{k}, \quad R^{W}(t, t-1)=\bigcup_{i=2}^{W} R_{i}
\end{gathered}
$$

where $w$ is the window base, $T$ is the transpose operator, $\times$ is the Cartesian product, and $\mathrm{U}$ is the union

Later, in step 6, they picked a suitable parameter $w$, where $w>1$, calculate $R^{w}(t, t-1)$ and forecast the enrollments as follows:

$F(t)=F(t-1) \circ R^{W}(t, t-1)$,

where $F(t), F(t-1)$ represent the forecasted fuzzy enrollment of year $t, t-1$ respectively and

Step 7: Defuzzify the forecasted fuzzy enrollment using a 3-layer backpropagation neural network.

Sullivan and Woodall [11] reviewed the first-order time-invariant and time-variant fuzzy time series models proposed by Song and Chissom[9-10] and compared with a time-invariant Markov model using linguistic labels with probability distributions.

Chen [12] proposed a simplified procedure to implement firstorder FTS with triangular Fuzzy membership function on the enrolment of Alabama University from the years 1971-1992. The MAPE of Chen was $3.11 \%$. Chen [12] procedure is similar to Song and Chissom [9] from steps 1-5 except in step 6, they established a fuzzy logical relationship group (FLRG) and

Step 7 Defuzzify the forecasted outputs using several simplified rules.

Hwang, Chen and Lee [13] adopted the differences of the enrolments on Song and Chissom's [9] procedure to forecast the enrolments of University of Alabama based on FTS.

Chen and Hwang [14] proposed a two-factor time-variant fuzzy time series model to forecast temperature.

Huarng [15] introduced the heuristic knowledge and establish the heuristic FLRG into Chen's [10] model to improve forecasting of university enrollment.

Huarng [16] examined the effect of interval length on the forecasting results. He proposed two heuristic approaches, namely distribution and average-based, to determine the length of the interval Chen [17] presented a high-order FTS model to forecast enrolment of Alabama University in their previous work [10].and obtained MAPE of $1.52 \%$.

Chen and Hsu [18] suggested first order and time-variant FTS model to forecast enrolments of the University of Alabama. Their procedure of Steps 1 and 2 are the same as Song and Chissom [9]. Nevertheless, in

Step 4: Sort the intervals based on the number of historical enrollment data in each interval from the highest to the lowest. Divide the interval having the largest, second largest, third largest, and fourth largest number of historical enrollment data into four, three, two and one intervals respectively. If there are no data distributed in an interval, then discard this interval. Lastly, a set of rules was used to determine whether the trend of the forecasting goes up or down and to forecast the enrolments.

Eleruja, Mu'azu and Dajab [19] implemented TFA and particle swarm optimization (PSO) on maximum temperature data of Zaria for the period 1990-2003 to forecast 2014 maximum temperature. The used the revised standard deviation of the distance between two consecutive data points to replace $D_{1}$ and $D_{2}$ in Song and Chissom [9].

Cheng, Chang and Yeh [20] implemented FTS with the trapezoidal Fuzzy approach (TFA) on the enrolment of Alabama University from the years 1971-1992. They obtained a MAPE of $2.66 \%$. They used the standard deviation of the data to replace the arbitrary numbers of $D_{1}$ and $D_{2}$ in Song and Chissom [7- 8] and fuzzified data using TFA.

Poulsen [21] utilized a new high-order FTS model, TFA, aggregation and PSO on enrolment of the University Of Alabama.

Konica and Hanelli [22] adopted fuzzy interference system toolbox in Matlab for a short-term load forecasting electricity consumption for Albania. Time, historical and forecasting value of the temperature and previous day load were used as the input to predict the next-day electricity consumption.

In this paper, we have only monthly UTHM electricity consumption from January 2011 to December 2017. Therefore, the FTS was applied to these data to forecast the UTHM monthly 2018 electricity consumption. The accuracy of FTS will be compared with historical data.

\section{Fuzzy Time Series (FTS)}

We adopted Poulsen's [21] algorithm of first-order FTS with trapezoidal fuzzification set in Microsoft Excel spreadsheet, but did not apply PSO. The input is the same month of electricity consumption from year 2011-2017, for example with the input of January electricity consumption from 2011-2017, the January 2018 electricity consumption will be forecasted. The process is repeated for February, March, ... till December. The following steps show the general procedure to be taken in order to forecast monthly 2018 electricity consumption.

1. Sort the values of the same month electricity consumption from 2011-2017 in ascending order.

2. Compute distance, $D_{i}$ between any two consecutive electricity consumptions in the sorted dataset as

$D_{i}=\left|\mathrm{x}_{i+1}-x_{i}\right|$

3. Find average distance, $A D$ between any two consecutive electricity consumptions in the sorted dataset as

$A D=\frac{1}{n-1} \sum_{i=1}^{n-1} D_{i}$

4. Compute the corresponding standard deviation, $\sigma_{A D}$ of the average distance as

$\sigma_{A D}=\frac{1}{n-1} \sum_{i=1}^{n-1}\left(D_{i}-A D\right)^{2}$

5. $D$ should be in the following interval

$A D-\sigma_{A D} \leq D \leq A D+\sigma_{A D}$

Eliminate the outlier $D_{i}$ which is not in the range.

6. Recalculate the revised average distance $A D_{r}$ from the remaining $D_{i}$

7. Define the universe of discourse

$U=\left[D_{M I N}-A D_{r}, D_{M A X}+A D_{r}\right]$

where $D_{M I N}$ is the minimum value of the electricity consumption while $D_{M A X}$ is the maximum value of the electricity consumption.

8. Fuzzify the universe of discourse using the trapezoidal fuzzification approach. In the trapezoidal fuzzy set, there is four quartets of trapezoidal fuzzy numbers $(a, b$, $c, d)$. The leftmost value of the trapezoidal set is $D_{M I N}-A D_{r}$, whereas the rightmost value of the trapezoidal set is $D_{M A X}+A D_{r}$ and the distance for each number of $a, b, c$ and $d$ are the revised average distance, $A D_{r}$.

9. Sometime a data may belong to two fuzzy sets, so to determine the data belong to which fuzzy set, the trapezoidal Fuzzy number will be used to find the membership degree: 


$$
\mu_{A}=\left\{\begin{array}{cc}
0 & x_{i}<a \\
\frac{x_{i}-a}{b-a}, & a \leq x_{i} \leq b \\
1 & b \leq x_{i} \leq c \\
\frac{d-x_{i}}{d-c}, & b \leq x_{i} \leq c \\
0, & x_{i}>d
\end{array}\right.
$$

10. The highest membership degree will be used to determine the membership of a fuzzy set.

11. Next, a Fuzzy set relationship will be determined. If the time series variable $F(t-1)$ as fuzzified as $A_{i}$ and $F(t)$ as $A_{j}$, then $A_{i}$ is related to $A_{j}$ and denoted as $A_{i} \rightarrow A_{j}$.

12. Then, fuzzy linear relation group (FLRG) will be determined by grouping the same fuzzy set which is related to more than one set.

13. Later, the midpoint of each of the FLRG will be computed.

14. The forecasted value will be the average value of the midpoint of the FLRG values.

\section{Error Analysis}

The performance of the above time series methods can be measured by absolute error (AE), mean absolute error (MAE), mean absolute percentage error, sum of square of error (SE), mean square error (MSE), root mean square error (RMSE) as below:

$A E=\mid$ error $|=| y_{i}-\hat{y}_{i} \mid$,

$M A E=\frac{\sum_{i=1}^{n}\left|y_{i}-\hat{y}_{i}\right|}{n}$,

$M A P E=\frac{\sum_{i=1}^{n} \frac{\left|y_{i}-\hat{y}_{i}\right|}{y_{i}}}{n} \times 100 \%$,

$S E=\mid$ error $\left.\right|^{2}=\left|y_{i}-\hat{y}_{i}\right|^{2}$,

$M S E=\frac{\sum_{i=1}^{n}\left|y_{i}-\hat{y}_{i}\right|^{2}}{n}$,

$R M S E=\sqrt{\frac{\sum_{i=1}^{n}\left|y_{i}-\hat{y}_{i}\right|^{2}}{n}}$,

where $y_{i}, \hat{y}_{i}$ are real and forecasted data respectively, $n$ is the number of real data. Here, MAE measures the average value of the absolute error or the average of the spread of error. All errors are assigned equal weights in MAE [23]. MAPE is a relative percentage error corresponds to MAE. Lewis [24] stressed that the MAPE is the most useful measure to compare the accuracy of forecasting methods as it measures relative performance. A MAPE which is less than 10 percent is considered as highly accurate forecasting, between $10-20$ percent is good forecasting, between $20-50$ percent is interpreted as reasonable forecasting and over 50 percent is inaccurate forecasting [24]. On the other hand, MSE measures the average of the squares of the errors, hence large errors are given additional weight [23]. Whereas RMSE is the square root of the MSE.

\section{Methodology}

The forecasting process of January 2018 electricity consumption will be started on the January data from the year 2011 to 2017 which is shown in Table 1 as the following steps:

Table 1: January data set

\begin{tabular}{|c|r|r|r|r|r|}
\hline Year & \multicolumn{1}{|c|}{ Jan } & & \multicolumn{1}{c|}{ Sort } & \multicolumn{1}{c|}{ D } & $|\mathrm{D}-\mathrm{AD}|^{\wedge} 2$ \\
\hline 2011 & 1757.133 & & 1757.133 & & \\
\hline 2012 & 2646.807 & & 2256.096 & 498.963 & 97822.05 \\
\hline 2013 & 2855.407 & & 2379.815 & 123.719 & 3903.605 \\
\hline 2014 & 2379.815 & & 2646.807 & 266.992 & 6527.697 \\
\hline 2015 & 2774.32 & & 2774.32 & 127.513 & 3443.91 \\
\hline 2016 & 2874.32 & & 2855.407 & 81.087 & 11048.29 \\
\hline 2017 & 2256.096 & & 2874.32 & 18.913 & 27984.22 \\
\hline & & & AD & 186.1978 & \\
\hline & & & Sigma & 158.498 & \\
\hline
\end{tabular}

1) The sorted values of the January electricity consumption from the year 2011-2017 in the current dataset in ascending order are shown in column 3 of Table 1.

2) Compute distance, $D$ using Eq. (1) and the results are shown in the fourth column of Table 1.

3) The average distance, $A D$ between any two consecutive electricity consumption in the sorted dataset was found as 186.1978 .

4) The corresponding standard deviation, $\sigma_{A D}$ of the average distance was obtained as 158.498 .

5) $D$ should be in the interval $27.6998 \leq D \leq 344.6959$.

Eliminate the outlier $D$ (498.963 and 18.913) which are not in the range.

6) The revised average distance $A D_{r}$ from the remaining $D$ was calculated as $A D_{r}=149.8278$

7) Define the universe of discourse $U=[1607.305,3024.148]$

8) The trapezoidal fuzzy sets were obtained as given in Table 2:

Table 2: Trapezoidal Fuzzy numbers (a, b, c, d)

\begin{tabular}{|c|c|c|c|r|}
\hline Fuzzy set & & Fuzzy & Numbers & \\
\hline & $\boldsymbol{a}$ & $\boldsymbol{b}$ & $\boldsymbol{c}$ & \multicolumn{1}{c|}{$\boldsymbol{c}$} \\
\hline $\mathrm{A}_{1}$ & 1607.305 & 1757.133 & 1906.961 & 2056.789 \\
\hline $\mathrm{A}_{2}$ & 1906.961 & 2056.789 & 2206.616 & 2356.444 \\
\hline $\mathrm{A}_{3}$ & 2206.616 & 2356.444 & 2506.272 & 2656.1 \\
\hline $\mathrm{A}_{4}$ & 2506.272 & 2656.1 & 2805.927 & 2955.755 \\
\hline $\mathrm{A}_{5}$ & 2805.927 & 2955.755 & 3105.583 & 3255.411 \\
\hline
\end{tabular}

Where the left most is

$D_{\text {MIN }}-A D_{r}=1757.133-149.8278=1607.305$. Then the following values will be added with $A D_{r}$. Next the values of $a$ and $b$ for the following fuzzy set are equal to the preceding values of $c$ and $d$ from preceding Fuzzy set. The right most value of the fuzzy set will not necessary equals to $D_{\text {MAX }}+A D_{r}$ but will be greater than it.

9. The fuzzified membership set of January electricity consumption is given in Table 3 . It is clearly shown that January 2011, 2014, 2015 belong to fuzzy set A1, A3 and A4. January 2012, 2013, 2016 and 2017 belong to both fuzzy sets, hence the formula (6) was used to determine their higher membership degree as given in columns 3 and 4 in Table 3. The fuzzied membership set was determined based on the highest membership degree. For example, electricity consumption in January 2012 (2646.807) belongs to fuzzy sets A3 and A4. The membership degrees of A3 and A4 are shown in columns 3 and 4 in Table 3 . The highest membership de- 
gree is A4 and thus the January 2012 data is fuzzified in Fuzzy set A4.

Table 3: Fuzzified membership set

\begin{tabular}{|c|c|c|c|c|}
\hline \multirow{2}{*}{$\frac{\text { Year }}{2011}$} & \multirow{2}{*}{$\begin{array}{c}\text { Jan } \\
1757.133\end{array}$} & \multicolumn{2}{|c|}{ Membership degree } & \multirow{2}{*}{$\begin{array}{c}\begin{array}{c}\text { Fuzzified } \\
\text { Data }\end{array} \\
\mathrm{A}_{1}\end{array}$} \\
\hline & & - & - & \\
\hline 2012 & 2646.807 & 0.062021 & 0.937979 & $\mathrm{~A}_{4}$ \\
\hline 2013 & 2855.407 & 0.669756 & 0.330244 & $\mathrm{~A}_{4}$ \\
\hline 2014 & 2379.815 & - & - & $\mathrm{A}_{3}$ \\
\hline 2015 & 2774.32 & - & - & $\mathrm{A}_{4}$ \\
\hline 2016 & 2874.32 & 0.543524 & 0.456476 & $\mathrm{~A}_{4}$ \\
\hline 2017 & 2256.096 & 0.669756 & 0.330244 & $\mathrm{~A}_{2}$ \\
\hline
\end{tabular}

10. The fuzzy logical relationships (FLR) were obtained as

$A_{1} \rightarrow A_{4}, \quad A_{4} \rightarrow A_{4}, \quad A_{4} \rightarrow A_{3}$,

$A_{3} \rightarrow A_{4}, \quad A_{4} \rightarrow A_{4}, \quad A_{4} \rightarrow A_{2}$.

11. Next, a fuzzy logical relation group (FLRG) were determined by grouping the same group of fuzzy set relationships as shown in Table 4.

\begin{tabular}{|c|c|c|c|}
\hline \multicolumn{1}{|c|}{ Table 4: FLRG } \\
Year & Jan & $\begin{array}{c}\text { Fuzzified mem- } \\
\text { bership set }\end{array}$ & FLRG \\
\hline 2011 & 1757.133 & $\mathrm{~A}_{1}$ & $A_{1} \rightarrow A_{4}$ \\
\hline 2012 & 2646.807 & $\mathrm{~A}_{4}$ & $A_{4} \rightarrow A_{2}, A_{3}, A_{4}$ \\
\hline 2013 & 2855.407 & $\mathrm{~A}_{4}$ & $A_{4} \rightarrow A_{2}, A_{3}, A_{4}$ \\
\hline 2014 & 2379.815 & $\mathrm{~A}_{3}$ & $A_{3} \rightarrow A_{4}$, \\
\hline 2015 & 2774.32 & $\mathrm{~A}_{4}$ & $A_{4} \rightarrow A_{2}, A_{3}, A_{4}$ \\
\hline 2016 & 2874.32 & $\mathrm{~A}_{4}$ & $A_{4} \rightarrow A_{2}, A_{3}, A_{4}$ \\
\hline 2017 & 2256.096 & $\mathrm{~A}_{2}$ & $A_{2} \rightarrow A_{2}$ \\
\hline
\end{tabular}

12. The midpoint of each of the FLRG is given in Table 5 .

Table 5: Midpoint of FLRG
\begin{tabular}{|l|l|l|r|}
\hline \multicolumn{1}{|c|}{ FLRG } & \multicolumn{3}{|c|}{ Midpoint } \\
\hline $\mathrm{A}_{\mathrm{1}^{-}>\mathrm{A}_{4}}$ & 2731.013 & & \\
\hline $\mathrm{A}_{4^{-}}>\mathrm{A}_{2}, \mathrm{~A}_{3}, \mathrm{~A}_{4}$ & 2131.702 & 2431.358 & 2731.013 \\
\hline $\mathrm{A}_{4^{-}}>\mathrm{A}_{2}, \mathrm{~A}_{3}, \mathrm{~A}_{4}$ & 2131.702 & 2431.358 & 2731.013 \\
\hline $\mathrm{A}_{3^{-}>\mathrm{A}_{4}}$ & 2731.013 & & \\
\hline $\mathrm{A}_{4^{-}}>\mathrm{A}_{2}, \mathrm{~A}_{3}, \mathrm{~A}_{4}$ & 2131.702 & 2431.358 & 2731.013 \\
\hline $\mathrm{A}_{4^{-}}>\mathrm{A}_{2}, \mathrm{~A}_{3}, \mathrm{~A}_{4}$ & 2131.702 & 2431.358 & 2731.013 \\
\hline $\mathrm{A}_{2^{-}>\mathrm{A}_{2}}$ & 2131.702 & & \\
\hline
\end{tabular}

13. Finally, the forecasted January electricity consumption is the average of the previous year electricity consumption as given in Table 6 .

Table 6: Forecast results

\begin{tabular}{|r|r|r|}
\hline \multicolumn{2}{|c|}{ Table 6: Forecast results } \\
\hline Year & 1757.133 & Forecasted \\
\hline 2011 & 2646.807 & 2731.013 \\
\hline 2012 & 2855.407 & 2431.358 \\
\hline 2013 & 2379.815 & 2431.358 \\
\hline 2014 & 2774.32 & 2731.013 \\
\hline 2015 & 2874.32 & 2431.358 \\
\hline 2017 & 2256.096 & 2431.358 \\
\hline & & 2131.702 \\
\hline
\end{tabular}

\section{Results and Discussions}

UTHM electricity consumption patterns versus month for years 2011-2018 is shown in Figure 1. It is noticed that the electricity consumption has increased since the year 2011. The electricity consumption fluctuates for each month. The electricity consump- tion in December 2017 is the minimum if compared to the same December month as 3 faculties of UTHM moved to Pagoh since Aug 2017. The year 2015 has the highest electricity consumption of $3869.05 \mathrm{MWh}$, while the year 2011 has the minimum electricity consumption if compared to other years. The electricity consumption for certain months are low than usual may because the month is mostly semester break of UTHM. There are fewer students in the campus and therefore, the electricity consumption will be less if compared to the months that are not semester break.

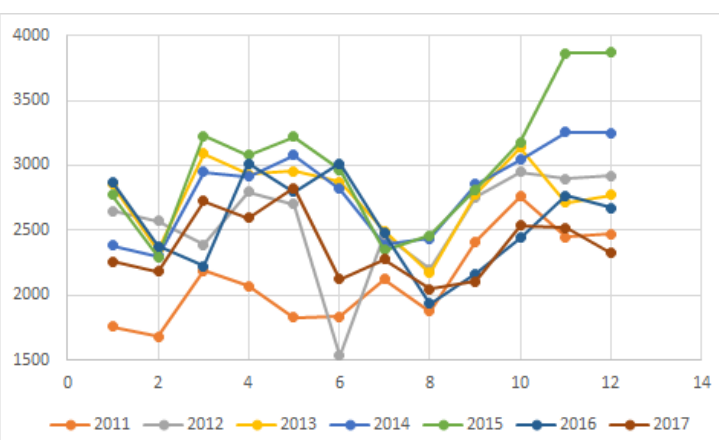

Fig. 1: Actual Load by years

Figure 2 shows the time series of UTHM electricity consumption continuously from Jan 2011-Dec 2017. The electricity consumption is range from $1500 \mathrm{MWh}$ to $4000 \mathrm{MWh}$. The time series seems is not stationary and is increasing. The electricity consumption in the year 2018 will be forecasted by using six different time series analysis methods.

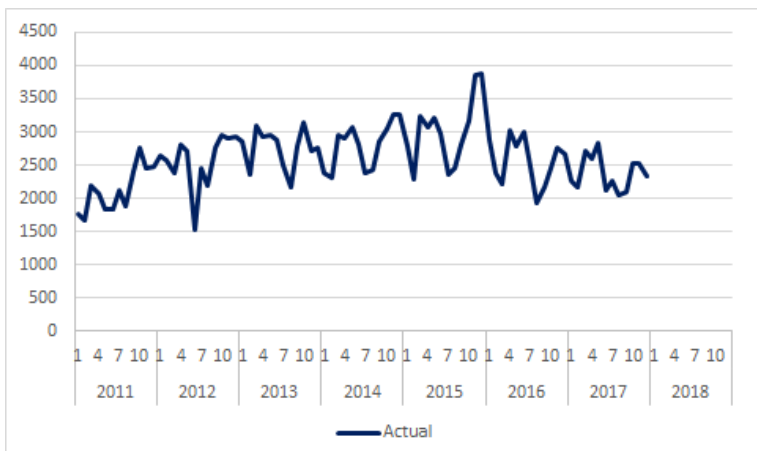

Fig. 2: Actual Electricity Consumption for all years

The actual UTHM electricity consumption (blue colour) from Jan 2011 to December 2017 and forecasted electricity consumption (red colour) using FTS from January 2012 to December 2018 were depicted in Figure 3. FTS uses the data in 2011 to forecast the electricity consumption for 2012 and so on. Hence, the forecasted results start from January 2012. FTS can forecast the pattern of the actual data quite close especially in May 2012 as the absolute percentage error (APE) in that month is the minimum of $0.02 \%$. The highest APE is on June 2017 which is $20.01 \%$.

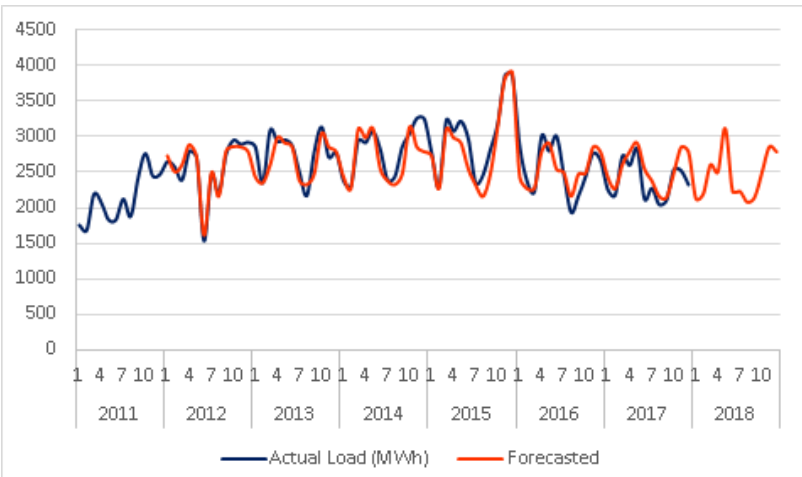

Fig. 3: Actual Electricity Consumption and FTS 
Table 7 gives the MAE, MAPE, MSE and RMSE values for FTS method.

\begin{tabular}{|c|c|c|c|c|}
\hline & MAE & MAPE $(\%)$ & MSE & RMSE \\
\hline FTS & 153.1087 & 5.74 & 43543.899 & 208.671 \\
\hline
\end{tabular}

\section{Conclusion}

FTS was applied on monthly UTHM electricity consumption from Jan 2011-December 2017 to forecast monthly 2018 UTHM electricity consumption. FTS gives $5.74 \%$ of MAPE which is quite low and can consider as high accuracy forecasting tool.

\section{Acknowledgment}

We would like to thank the UTHM Research Fund and UTHM Tier 12018 research grant vote number H258for financial support of this project.

\section{References}

[1] Zadeh LA, "Fuzzy sets", Information and Control, Vol. 8, (1965), pp.338- 353.

[2] Song Q, Chissom BS, "Fuzzy time series and its models", Fuzzy Sets and Systems, Vol. 54, (1993), pp. 269-277.

[3] Zadeh LA, "Outline of a new approach to the analysis of complex system and decision processes", IEEE Transactions on Systems, Man, and Cybernetics, Vol. 3, No.1, (1973), pp. 28- 44.

[4] Zadeh LA, "The concept of a linguistic variable and its application to approximate reasoning - Part I", Information Sciences, Vol. 8, (1975), pp. 199 - 249.

[5] Zadeh LA, "The concept of a linguistic variable and its application to approximate reasoning - Part II", Information Sciences, Vol.8, (1975), pp. 301- 357.

[6] Zadeh LA, 1975c. "The concept of a linguistic variable and its application to approximate reasoning \pm Part III”. Information Sciences, Vol.9, No.1, pp. 43- 80.

[7] Pedregal DJ \& Trapero JR, "Mid-term hourly electricity forecasting based on a multi-rate approach", Energy Conversion and Management, Vol. 51, (2010), pp. 105-111.

[8] Almeshaiei E \& Soltan H, "A methodology for Electric Power Load Forecasting”, Alexandria Engineering Journal, Vol. 50, (2011), pp. 137-144

[9] Song Q \& Chissom BS, "Forecasting enrollments with fuzzy time series: Part I", Fuzzy Sets and Systems, Vol. 54, (1993), pp. 1-9.

[10] Song Q, Chissom BS, "Forecasting enrollments with fuzzy time series: Part II", Fuzzy Sets and Systems, Vol. 62, (1994), pp. 1-8.

[11] Sullivan J \& Woodall WH, "A comparison of fuzzy forecasting and Markov modelling”. Fuzzy Sets and Systems, Vol. 64, (1994), pp.279-293.

[12] Chen SM, "Forecasting enrollments based on fuzzy time series", Fuzzy Sets and Systems, Vol. 81, No. 3, (1996), pp.311- 319.

[13] Hwang JR, Chen SM \& Lee CH, "Handling forecasting problems using fuzzy time series", Fuzzy Sets and Systems, Vol. 100, No.2, (1998), pp. 217- 228.

[14] Chen SM \& Hwang JR, "Temperature predication using fuzzy time series", IEEE Transactions on Systems, Man, and Cybernetics \pm Part B: Cybernetics Vo. 30, No.2, (2000), pp. 263- 275.

[15] Huarng K, "Heuristic models of fuzzy time series for forecasting", Fuzzy Sets and Systems, Vol. 123, (2001), pp. 369-386.

[16] Huarng K, "Effective lengths of intervals to improve forecasting in fuzzy time series", Fuzzy Sets and Systems, Vol. 123, (2001), pp. 387-394.

[17] Chen, SM, "Forecasting enrolments based on high-order fuzzy time series", Cybernetics and Systems: An International Journal, Vol. 33, (2002), pp.1-16.

[18] Chen SM \& Hsu CC, "A New Method to Forecast Enrolments Using Fuzzy Time Series", International Journal of Applied Science and Engineering, Vol. 2, No. 3, (2004), pp. 234-244.

[19] Eleruja SA, Mu'azu MB \& Danshik DD, “Application of trapezoidal fuzzification approach(TFA) and particle swarm optimization (PSO) in fuzzy time series(FTS)forecasting", Proceedings of IEEE International Conference on Neural Networks. Vol. 3, No.4, (2004), pp.524-531.
[20] Cheng CH, Chang JR \& Yeh CA, Entropy-based and trapezoid fuzzification-based fuzzy time series approaches for forecasting IT project cost”, Technological Forecasting \& Social Change, Vol. 73 (2006), pp. 524-542.

[21] Poulsen JR. "Developing a new forecasting model based on high order fuzzy time series" Master thesis of Aalborg University Esbjerg, (2009).

[22] Konica JA \& Hanelli L, "Forecasting Next-Day the Electricity Demand Based On Fuzzy Logic Method Case for Albania", Journal of Multidisciplinary Engineering Science and Technology, Vol. 3, No.12, (2016), pp. 6172-6180.

[23] Ostertagová E \& Ostertag O. "Forecasting Using Simple Exponential Smoothing Method", Acta Electrotechnica et Informatica, Vol. 12, No. 3, (2012), pp. 62-66.

[24] Lewis CD, Industrial and Business Forecasting Methods, London, Butterworths, (1982). 